\title{
Ultrasound-assisted emulsification-microextraction and spectrophotometric determination of cobalt, nickel and copper after optimization based on Box-Behnken design and chemometrics methods
}

\author{
Zohreh Doroudi $^{1^{*}}$, Ali Niazi ${ }^{2}$ \\ ${ }^{1}$ Department of Chemistry, College of Science, Yadegar-e-Imam Khomeini (RAH) Shahre Rey Branch, Islamic Azad \\ University, Tehran, Iran \\ ${ }^{2}$ Department of Chemistry, Faculty of Science, Arak Branch, Islamic Azad University, Arak, Iran \\ "Corresponding author: e-mail: Zohreh.Doroudi@gmail.com
}

\begin{abstract}
A fast, simple, and economical method for extraction, preconcentration and determination of cobalt, nickel and copper as their 1-(2-pyridilazo) 2-naphthol (PAN) complexes based on ultrasound-assisted emulsification-microextraction (USAEME) and multivariate calibration of spectrophotometric data is presented. Various parameters affecting the extraction efficiency were optimized both with univariate and Box-Behnken design. The resolution of ternary mixtures of these metallic ions was accomplished by using partial least-squares regression (PLS), orthogonal signal correction- partial least-squares regression (OSC-PLS), and orthogonal signal correction- genetic algorithmspartial least-squares regression (OSC-GA-PLS). Under the optimum conditions, the calibration graphs were linear in the range of 2.0-150.0, 2.0-120.0 and 2.0-150.0 ng mL ${ }^{-1}$ for $\mathrm{Co}^{2+}, \mathrm{Ni}^{2+}$, and $\mathrm{Cu}^{2+}$, respectively, with a limit of detection of $0.14\left(\mathrm{Co}^{2+}\right), 0.13\left(\mathrm{Ni}^{2+}\right)$ and $0.14 \mathrm{ng} \mathrm{mL}^{-1}\left(\mathrm{Cu}^{2+}\right)$ and the relative standard deviation was $<2.5 \%$. The method was successfully applied to the simultaneous determination of these cations in different samples.
\end{abstract}

Keywords: ultrasound-assisted emulsification-microextraction, chemometrics, cobalt, nickel, copper.

\section{INTRODUCTION}

Heavy metals are sometimes called "trace elements". The determination of heavy metals at trace levels in environmental samples is an important part of chemistry due to their positive or negative effects on the human body ${ }^{1}$. Industrial processes can release heavy metals into their wastewater streams, resulting in potential contamination of the environment. Among those cobalt, nickel and copper are metals, which appear together in many real samples. So, it is very important to determine their concentrations ${ }^{2}$.

Sample preparation represents a major challenge and a very important step in the development and application of an analytical method. In general, this step consists of an extraction and preconcentration procedure of target compounds from a sample matrix ${ }^{3}$. Various sample preparation methods including solid-phase microextraction (SPME) fibers ${ }^{4}$, hollow fiber solid phase microextraction $(\mathrm{HF}-\mathrm{SPME})^{5}$, micro-solid phase extraction (uSPE) ${ }^{6}$, dispersive liquid-liquid microextraction (DLLME) ${ }^{7,8}$, Ionic liquids (ILs) applied in liquid-phase microextraction (LPME) ${ }^{9}$, and surfactant-assisted emulsification dispersive liquid-liquid microextraction (SAE-DLLME) ${ }^{\mathbf{1 0}}$ have been developed for this purpose. Regueiro et al. ${ }^{3}$ coupled two well-known procedures, namely dispersive liquid-liquid microextraction (DLLME) ${ }^{\mathbf{1 1}}$ and ultrasoundassisted liquid-liquid microextraction (USALLE) ${ }^{12}$, and developed the so-called ultrasound-assisted emulsification-microextraction (USAEME) procedure. This procedure differs slightly from that used in conventional DLLME, the difference being that instead of a disperser solvent, US energy is applied as a means of dispersing the extraction solvent, meaning the disperser solvent can be omitted from the extraction procedure ${ }^{13}$.

Several spectrometric techniques such as flame graphite furnace atomic absorption spectrometry (GFAAS) ${ }^{14}$, flame atomic absorption spectrometry (FAAS $)^{15}$, inductively coupled plasma optical emission spectrometry (ICP$\mathrm{OES})^{16}$, inductively coupled plasma mass spectrometry
$(\mathrm{ICP}-\mathrm{MS})^{17}$ and spectrophotometric ${ }^{10,18}$ have been widely used for determination of trace amounts of heavy metal ions in environmental samples.

A derivatization is an important tool for analysis; especially complex-forming reactions are widely used for separation and/or preconcentration before spectrophotometric determination. Different Chelating agents have been proposed, such as 2-(2'-Thiazolylazo) p-cresol (TAC), 1-(2-thiazolylazo) 2-naphthol (TAN), 1-(2-pyridylazo) 2-naphthol (PAN) ${ }^{19-21}$. PAN forms highly colored and stable complexes with a number of metals. The simultaneous determination of these ions by use of the UV-Vis spectrophotometry techniques and conventional metallochromic indicators in aqueous solution is difficult because, generally, the absorption spectra overlap and the curves are not suitable for quantitative evaluation ${ }^{22}$.

Nowadays quantitative spectrophotometry has been greatly improved by the use of a variety of multivariate statistical methods, particularly partial least squares regression (PLS). It has been shown that PLS is a reasonable choice for the resolution of overlapping signals and quantitative analysis over a wide range of conditions ${ }^{23-26}$.

Orthogonal signal correction (OSC) is a preprocessing technique used for removing the information unrelated to the target variables based on constrained principal component analysis. OSC is a suitable preprocessing method for partial least squares calibration of mixtures without loss of prediction capacity using the spectrophotometric method.

Among the different variable selection strategies, genetic algorithms (GAs) is an interesting, flexible and widely used alternative ${ }^{27-30}$. Genetic algorithms is a stochastic method for optimization based on the evolution process of living beings in which simplicity and effectiveness have been applied to the various types of optimization problems in many scientific fields ${ }^{31}$.

This work presents the use of genetic algorithms in combination with an orthogonal signal correction-partial least squares (OSC-PLS) method for the variable selec- 
tion process to determine ternary mixtures of nickel, cobalt and copper in water samples. A Box-Behnken design was used in order to find the optimum conditions for the method through response surface methodology.

\section{PREPARATION AND CHARACTERIZATION}

\section{Reagents and chemicals}

All reagents were of an analytical reagent grade. The water utilized in all studies was double-distilled and deionized. The 1-(2-pyridylazo) 2-naphthol (PAN) (Sigma, Shanghai, China) was used as chelating agent. All solvents, such as chloroform, carbon tetrachloride, dichloromethane, chlorobenzene and ethanol, were purchased from Merck (Darmstadt, Germany). Stock solutions (1000 $\mathrm{mg} \mathrm{L}^{-1}$ ) of copper, nickel and cobalt were purchased from Merck (Darmstadt, Germany). The working standard solutions were made by an appropriate dilution daily as required. A stock PAN solution $\left(2.0 \times 10^{-3} \mathrm{M}\right)$ in Ethanol was prepared by dissolving the solid reagent. This solution was spectrophotometrically stable for at least a week. Universal buffer solutions were prepared by Lurie ${ }^{32}$.

\section{Apparatus}

All absorbance measurements were obtained using a Hewlett-Packard 8453 diode array spectrometer controlled by a Hewlett-Packard computer, between 400 and $700 \mathrm{~nm}$ digitized every $1 \mathrm{~nm}$. A model 780 digital Metrohm $\mathrm{pH}$ meter equipped with a combined glasscalomel electrode was used for the $\mathrm{pH}$ adjustments. The centrifuge was performed by a Sigma 3K30). An ultrasonic (VGT-1740QTD, Taiwan) water bath with a temperature control and a digital timer was used to emulsify the extraction solvent. OSC and PLS models were performed with the PLS Toolbox, Version 4.0 (Eigenvector Technologies). The GAs program was written in MATLAB by Leardi. Box-Behnken design was accomplished with Minitab Version 16.

\section{Ultrasound-assisted emulsification-microextraction (USAEME)}

$10.0 \mathrm{~mL}$ standard solution containing different concentration of $\mathrm{Co}^{2+}, \mathrm{Ni}^{2+}$ and $\mathrm{Cu}^{2+}, 2.0 \mathrm{~mL}$ of the buffered solution $(\mathrm{pH} 5.5), 1.0 \mathrm{~mL}$ of PAN solution $\left(2.0 \times 10^{-3}\right.$ $\mathrm{M})$ were placed in a $12 \mathrm{~mL}$ screw cap glass test tube with a conical bottom. In this step, metal ions reacted with PAN to form related complexes. After $15 \mathrm{~min}$, the tube was placed into the ultrasonic water bath in such a way that the level of both liquids (bath and sample) was the same. Then $300 \mu \mathrm{L}$ of a mixture of $\mathrm{CCl}_{4}$ and $\mathrm{CHCl}_{3}$ (extraction solvents 1:2 v/v\%) were injected into the sample solution by using a syringe. The extraction was completed under ultrasound in $3.5 \mathrm{~min}$ at the predetermined temperature $\left(\sim 32^{\circ} \mathrm{C}\right)$. Then, the emulsion was disrupted by centrifugation at $3000 \mathrm{rpm}$ for $3.5 \mathrm{~min}$ and thus the organic phase was sedimented at the bottom of the tube. The upper aqueous phase was removed with a syringe. The sedimented phase dried by passing nitrogen gas. Finally, the residue was dissolved in 0.5 $\mathrm{mL}$ EtOH and was analyzed by UV-Vis spectrophotometric. The experimental setup used in this investigation is illustrated in Figure 1.

\section{Real samples preparation before USAEME}

In this experiment, water samples and synthetic samples were selected for validating the proposed method. Wastewater samples were collected from Arak city. Prior to the preconcentration procedure, all the water samples were filtered through a $0.45 \mu \mathrm{m}$ pore size membrane filter to remove suspended particulate matter, then adjusted to $\mathrm{pH} 5.5$ and then stored in $4^{\circ} \mathrm{C}$.

\section{RESULTS AND DISCUSSION}

\section{Preliminary experiments}

In the USAEME method, there are several factors that would significantly affect the extraction efficiency, such as the types and volumes of extractant, ultrasonic time, the $\mathrm{pH}$ of the solution, ionic strength, concentration of ligand, centrifugation speed and time.

The selection of the extraction solvent is very important. The solvents with higher density than water, immiscibility with water, good solubility toward the chelate of the analytes and forming a stable emulsion system were considered for the extraction. Carbon tetrachloride $\left(\mathrm{CCl}_{4}\right)$, chloroform $\left(\mathrm{CHCl}_{3}\right)$, chlorobenzene $\left(\mathrm{C}_{6} \mathrm{H}_{5} \mathrm{Cl}\right)$, dichloromethane $\left(\mathrm{CH}_{2} \mathrm{Cl}_{2}\right)$ were examined. Then an appropriate mixture of extraction solvents was tested. The results show that the highest absorbance was obtained with carbon tetrachloride and chloroform with ratio 1:2 $\mathrm{v} / \mathrm{v} \%$. The combined use of $\mathrm{CHCl}_{3}$ and $\mathrm{CCl}_{4}$ as extractant solvent together allowed the effective extraction of these ions from the selected samples.

The Volume of extraction solvent is a crucial parameter that has an important effect on the extraction efficiency. Repeatability of results, extraction efficiencies and volume of deposited organic phase are affected by the volume of extraction solvent used. Concentrations of analytes in the organic phase deposit were reduced as

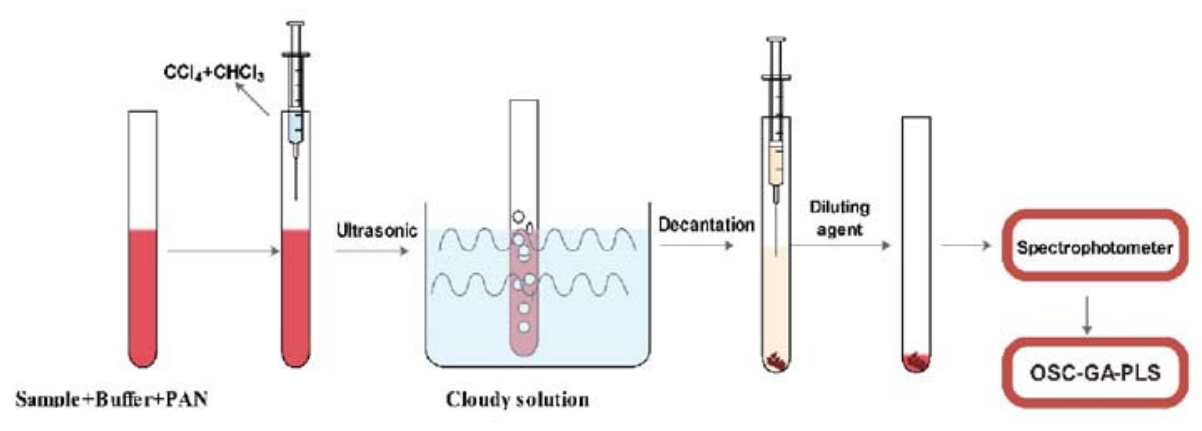

Figure 1. Schematic USAEME and chemometrics procedure 
the volume of extraction solvent increased as an effect of dilution; nevertheless, the amount of extracted analyte was increased. To study the effect of extraction solvents, different volumes of carbon tetrachloride and chloroform with ratio $1: 2 \mathrm{v} / \mathrm{v} \%$ in the range of $100-500 \mu \mathrm{L}$ were subjected to the extraction procedure. The results show that absorbance increased with the volume of extraction solvent increasing to $400 \mu \mathrm{L}$ and then nearly constant.

Metal complexation with PAN is very dependent on the $\mathrm{pH}$ of the solution. The effect of $\mathrm{pH}$ on the absorption of PAN complexes of $\mathrm{Co}^{2+}, \mathrm{Ni}^{2+}$ and $\mathrm{Cu}^{2+}$ was studied in the range of 3.0-7.0 using a universal buffer. It can be seen that when $\mathrm{pH}$ value is nearly 5 , the absorbance of all complexes increased. The progressive decrease in extraction at low $\mathrm{pH}$ is due to the competition of the hydrogen ion with the analyte for reaction with PAN. At higher $\mathrm{pH}$ values, the hydrolysis of cations occurs.

Dispersion is the key step in determining whether extraction is successfully carried out or not. Sonication produces fine droplets of organic solvent into the aqueous bulk and results in the generation of a high contact area between the aqueous phase and the extraction solvent. Sonication time was optimized in the range of 1-10 min under constant experimental conditions. The results show that absorbance increased by increasing the extraction time up to $3.5 \mathrm{~min}$. After $3.5 \mathrm{~min}$, the absorbance remained nearly constant.

Extraction time is one of the most important factors in the extraction procedure. In USAEME, extraction time is defined as the time between injection of the extraction solvent and the end of the sonication stage. In this work, the extraction time was varied using the values of 4-20 min for sample solution. Results revealed that the time, in the range studied, does not obviously affect the efficiency of USAEME.

The influence of PAN volume on the extraction was evaluated in the range of $300-1500 \mu \mathrm{L}$ of PAN. The absorbance was increased by increasing PAN volume, which was well expected. It seems that after addition $1000 \mu \mathrm{L}$ of ligand, slight reduction of extraction in high concentration of PAN is due to the extraction of PAN itself, which can easily saturate the small volume of extraction solvent. Therefore, the volume of $1000 \mu \mathrm{L}$ was chosen as the optimum amount of the determination of the heavy metal ions.

The rate of complex formation of PAN with $\mathrm{Co}^{2+}$, $\mathrm{Ni}^{2+}$ and $\mathrm{Cu}^{2+}$ was low, and at room temperature, the color of complexes reached a maximum in $15 \mathrm{~min}$. So reaction time was considered 15 minutes.

Generally, addition of salt can decrease the solubility of analytes in the aqueous phase and promote the transfer of the analytes towards the organic phase. The influence of ionic strength on USAEME performance was evaluated by adding various amounts of sodium chloride in the range $0-10 \%(\mathrm{w} / \mathrm{v})$ while the other parameters were kept constant. There was no significant effect on the extraction efficiency of target compounds.

A major parameter in USAEME that affects the formation of microdroplets from the extraction of solvent in the aqueous phase is centrifugation. The rate of centrifugation was adjusted between 1000 to $5000 \mathrm{rpm}$ for 5-2 minutes. The results showed that a clear upper phase was created, and phase separation was complete when the centrifugation time was 3.5 min and speed was $3000 \mathrm{rpm}$. Thus, these values were selected as optimal conditions for further testing.

\section{Optimization of significant variables using Box-Behnken design}

The traditional optimization procedure varying "one-variable-at-a-time", is a strategy based on experience that does not guarantee the attainment of a true optimum of the extraction conditions. The one-at-a-time design is a classical univariate method which consists of investigating the response for each factor while all other factors are held at a constant level ${ }^{33}$. Conversely, the chemometrics approach relies on a rational experimental design, which allows the simultaneous variation of all experimental factors, saving time and materials. The Box-Behnken design (BBD) ${ }^{\mathbf{3 4}}$ is probably the most widely used experimental design applied for fitting a second-order response surface.

An optimization procedure was applied in order to find out the exact values of the most important factors. The design consisted of 27 sets of experiments carried out according to the Box-Behnken technique as shown in Table 1. The experimental ranges selected for independent variables were: volume of ligand $\left(\mathrm{X}_{1}\right.$ : 800-1200 $\mu \mathrm{L})$, sample $\mathrm{pH}\left(\mathrm{X}_{2}: 4-7\right)$, extracting agent volume $\left(\mathrm{X}_{3}: 200-400 \mu \mathrm{L}\right)$, sonication time $\left(\mathrm{X}_{4}: 1-5 \mathrm{~min}\right)$. These ranges were selected based on a prior experiment about the system under study. The factor levels were coded as -1 (low), 0 (central point) and +1 (high). The design of experiments of Box-Behnken and the values of response $\mathrm{Y}$ under the different experimental combinations are presented in Table 1.

After obtaining the model and analyzes, it was found that the number of terms such as $\mathrm{X}_{1} \mathrm{X}_{2}, \mathrm{X}_{1} \mathrm{X}_{3}, \mathrm{X}_{2} \mathrm{X}_{4}$, $\mathrm{X}_{3} \mathrm{X}_{4}, \mathrm{X}_{1}^{2}, \mathrm{X}_{4}^{2}$ did not give significant effect on response. Therefore, to reduce the complexity and increase the accuracy, the second time modeling was performed by omitting these in significant terms. The improved equation is as Equation (1).

$$
\begin{aligned}
& \mathrm{Y}=0.771+0.145 \mathrm{X}_{1}+0.136 \mathrm{X}_{2}+0.091 \mathrm{X}_{3}+0.042 \mathrm{X}_{4}- \\
& -0.051 \mathrm{X}_{2}+0.048 \mathrm{X}_{2}^{2}+0.055 \mathrm{X}_{3}^{2}
\end{aligned}
$$

The positive values for the measured responses in regression equation indicated the synergistic effect (optimization), while the negative values represent the inverse relationship/antagonistic effects ${ }^{35}$. The derivatization of this general equation as $(\mathrm{pH})$, sonication time, $\left(\mathrm{V}_{\text {ext }}\right)$ and $\left(\mathrm{V}_{\text {ligand }}\right)$ results in four new equations:

$\frac{\partial Y}{\partial X_{1}}, \frac{\partial Y}{\partial X_{2}}, \frac{\partial Y}{\partial X_{3}}$ and $\frac{\partial Y}{\partial X_{4} \text { were each equated to zero and }}$ the resulting four equations were solved simultaneously to obtain the values of $\mathrm{X}_{1}, \mathrm{X}_{2}, \mathrm{X}_{3}$ and $\mathrm{X}_{4}$ corresponding to the maximum of $Y$. The optimum values of the tested parameters were obtained as follows: $\mathrm{X}_{1}=1000, \mathrm{X}_{2}=$ 5.5, $\mathrm{X}_{3}=300$ and $\mathrm{X}_{4}=3.5$.

\section{Statistical analysis}

According to the results of Table 2, the analysis of variance (ANOVA) was used to evaluate the significance of the model equation and related terms. 
Table 1. Factors and their levels in Box-Behnken design and observed response

\begin{tabular}{|l|c|c|c|c|c|}
\hline \multirow{2}{*}{ Run No. } & \multicolumn{3}{|c|}{ Actual level of factors } & \multicolumn{2}{c|}{ Absorbance } \\
\cline { 2 - 5 } & $\mathrm{X}_{1}$ & $\mathrm{X}_{2}$ & $\mathrm{X}_{3}$ & $\mathrm{X}_{4}$ & 0.850 \\
\hline 2 & 1200 & 5.5 & 300 & 1 & 0.575 \\
\hline 3 & 800 & 5.5 & 200 & 5 & 0.810 \\
\hline 4 & 1000 & 5.5 & 200 & 3 & 0.858 \\
\hline 5 & 1200 & 5.5 & 400 & 3 & 0.869 \\
\hline 6 & 1000 & 4 & 400 & 3 & 0.989 \\
\hline 7 & 1200 & 5.5 & 400 & 3 & 1.086 \\
\hline 8 & 1000 & 7 & 200 & 3 & 0.547 \\
\hline 9 & 1000 & 4 & 300 & 5 & 0.528 \\
\hline 10 & 800 & 5.5 & 300 & 5 & 0.923 \\
\hline 11 & 1000 & 7 & 300 & 3 & 0.085 \\
\hline 12 & 1200 & 5.5 & 300 & 3 & 0.882 \\
\hline 13 & 1200 & 4 & 300 & 3 & 1.114 \\
\hline 14 & 1200 & 7 & 300 & 3 & 0.748 \\
\hline 15 & 1000 & 5.5 & 300 & 5 & 0.482 \\
\hline 16 & 800 & 4 & 300 & 1 & 0.709 \\
\hline 17 & 1000 & 4 & 200 & 3 & 0.890 \\
\hline 18 & 1000 & 7 & 400 & 3 & 1.017 \\
\hline 19 & 1000 & 7 & 400 & 5 & 0.791 \\
\hline 20 & 800 & 5.5 & 300 & 1 & 0.970 \\
\hline 21 & 1000 & 5.5 & 300 & 5 & 0.673 \\
\hline 22 & 1000 & 4 & 400 & 1 & 0.691 \\
\hline 23 & 800 & 5.5 & 300 & 3 & 0.897 \\
\hline 24 & 1000 & 5.5 & 200 & 1 & 0.814 \\
\hline 25 & 800 & 7 & 300 & 3 & 0.701 \\
\hline 27 & 1000 & 5.5 & 300 & 3 & 0.835 \\
\hline
\end{tabular}

Table 2. Analysis of variance (ANOVA) evaluation of linear, quadratic and interaction terms for each response variable

\begin{tabular}{|c|c|c|c|c|c|}
\hline Variables & $\mathrm{DF}^{\mathrm{a}}$ & $S S^{b}$ & $\mathrm{MS}^{\mathrm{c}}$ & F-values & $p$-value \\
\hline Model & 14 & 0.6605 & 0.0471 & 22.05 & 0.000 \\
\hline $\mathrm{X}_{1}$ & 1 & 0.2696 & 0.2696 & 125.97 & 0.000 \\
\hline $\mathrm{X}_{2}$ & 1 & 0.2218 & 0.2218 & 103.68 & 0.000 \\
\hline$X_{3}$ & 1 & 0.0993 & 0.0992 & 46.39 & 0.000 \\
\hline $\mathrm{X}_{4}$ & 1 & 0.0209 & 0.0209 & 9.80 & 0.009 \\
\hline $\mathrm{X}_{1}^{2}$ & 1 & 0.0022 & 0.0014 & 1.04 & 0.329 \\
\hline $\mathrm{X}_{2}^{2}$ & 1 & 0.0093 & 0.0095 & 4.35 & 0.059 \\
\hline $\mathrm{X}_{3}^{2}$ & 1 & 0.0126 & 0.0001 & 5.93 & 0.031 \\
\hline $\mathrm{X}_{4}{ }^{2}$ & 1 & 0.0002 & 0.0098 & 0.10 & 0.761 \\
\hline$X_{1} X_{2}$ & 1 & 0.0025 & 0.0000 & 1.18 & 0.300 \\
\hline $\mathrm{X}_{1} \mathrm{X}_{3}$ & 1 & 0.0043 & 0.0024 & 2.05 & 0.178 \\
\hline $\mathrm{X}_{1} \mathrm{X}_{4}$ & 1 & 0.0001 & 0.00037 & 0.05 & 0.828 \\
\hline $\mathrm{X}_{2} \mathrm{X}_{3}$ & 1 & 0.01026 & 0.0042 & 4.79 & 0.049 \\
\hline $\mathrm{X}_{2} \mathrm{X}_{4}$ & 1 & 0.00004 & 0.0000 & 0.0000 & 0.967 \\
\hline $\mathrm{X}_{3} \mathrm{X}_{4}$ & 1 & 0.00034 & 0.0021 & 0.16 & 0.696 \\
\hline Residual & 12 & 0.02568 & 0.0023 & & \\
\hline Lack-of-Fit & 10 & 0.0219 & 0.0026 & 1.16 & 0.548 \\
\hline Pure Error & 2 & 0.0037 & 0.00081 & & \\
\hline Total & 26 & 0.6862 & & & \\
\hline
\end{tabular}

$R^{2}=96.26$; Predicted $R^{2}=89.05 ;$ Adjusted $R^{2}=91.89$. ${ }^{a} D F$ : Degree of freedom, ${ }^{b} S S=$ Sum of squares, 'MS: Mean squares.

The experimental data were evaluated with various descriptive statistical analyses such as $p$-value, degrees of freedom (DF), the sum of squares (SS), determination coefficient $\left(\mathrm{R}^{2}\right)$ and adjusted determination of coefficient $\left(\mathrm{R}_{\mathrm{a}}^{2}\right)$. The model equation and related terms were considered to be significant if $p$-values were less than 0.05 ( $p$-value at $95 \%$ confidence level). The goodness of fit of the model was checked by the correlation coefficient $\left(\mathrm{R}^{2}\right)$. The $\mathrm{R}^{2}$ value of 0.9626 indicated that $96.26 \%$ of the variability was explained by the model and only 0.374 was as a result of chance. The value of $\mathrm{R}^{2}(96.26 \%)$ also indicates good agreement between the experimental and predicted values of response. The lack-of-fit measures the failure of the model to represent data in the experimental domain at points which are not included in the regression ${ }^{36}$. The $p$-value of lack of fit
0.548 indicated that the quadratic model is statistically significant for the response.

\section{Interference study}

The influence of various species on the absorbance of a solution mixture containing $20.0 \mathrm{ng} \mathrm{mL} \mathrm{L}^{-1}$ of $\mathrm{Ni}^{2+}$, $10.0 \mathrm{ng} \mathrm{mL}{ }^{-1}$ of $\mathrm{Co}^{2+}$ and $20.0 \mathrm{ng} \mathrm{mL}{ }^{-1}$ of $\mathrm{Cu}^{2+}$ was investigated. An ion was considered as interference when its presence produced a variation in the absorbance of the sample greater than 5\%. Among the interfering ions tested; the ions $\mathrm{Na}^{+}, \mathrm{Li}^{+}, \mathrm{K}^{+}, \mathrm{No}_{3}{ }^{-}$and $\mathrm{Br}^{-}$did not interfere at concentrations 1000 times higher than those of the analytes. The ions $\mathrm{Mg}^{2+}, \mathrm{Ca}^{2+}$ did not interfere up to 500 times higher than those of the analytes. The ion $\mathrm{Cd}^{2+}$ did not interfere up to 20 times higher and the ion $\mathrm{Pb}^{2+} 10$ times higher than those of the analytes. 
The ions $\mathrm{Zn}^{2+}, \mathrm{Fe}^{2+}$ did not interfere up to 5-fold excess over analytes.

However, PLS calibration can implicitly model some interference, whenever the calibration solutions and samples have similar compositions and interferences are included in variable concentrations in the calibration set. This allows the interference to be overcome without previous separation and makes the method more robust.

\section{Analytical performance of the method}

Under the optimal conditions, calibration curves were constructed for the determination of $\mathrm{Ni}^{2+}, \mathrm{Co}^{2+}$ and $\mathrm{Cu}^{2+}$ ions, according to the mentioned procedure. Linearity was within the range of $2.0-120.0 \mathrm{ng} \mathrm{mL}^{-1}$ for $\mathrm{Ni}^{2+}, 2.0-150.0 \mathrm{ng} \mathrm{mL}{ }^{-1}$ for $\mathrm{Co}^{2+}$ and $2.0-150.0 \mathrm{ng}$ $\mathrm{mL}^{-1}$ for $\mathrm{Cu}^{2+}$ in the initial solution. The correlation of determination $\left(\mathrm{r}^{2}\right)$ was 0.997 for $\mathrm{Ni}^{2+}, 0.996$ for $\mathrm{Co}^{2+}$ and 0.997 for $\mathrm{Cu}^{2+}$ ions. The limit of detection is defined as $L O D=3 S_{b} / m$, where $S_{b}$ is the standard deviation of 10 replicates blank signals and $\mathrm{m}$ is the slope of the calibration curve after preconcentration. For a sample volume of $10 \mathrm{~mL}$, it was found to be $0.13 \mathrm{ng} \mathrm{mL}^{-1}$ for $\mathrm{Ni}^{2+}, 0.14 \mathrm{ng} \mathrm{mL}^{-1}$ for $\mathrm{Co}^{2+}$ and $0.14 \mathrm{ng} \mathrm{mL}{ }^{-1}$ for $\mathrm{Cu}^{2+}$ ions. The preconcentration factor was 200 , as the original volume used in the present experiment was $10 \mathrm{~mL}$ and a final extract volume of approximately $50 \mu \mathrm{L}$. In order to test the reproducibility of the proposed method Intra and inter-day precision was performed by measuring the absorbance of spiked water samples $\left(40.0 \mathrm{ng} \mathrm{mL}{ }^{-1}\right.$ each of ions) at five different times during the single day and on five subsequent days respectively. The percent relative standard deviation (RSD) was calculated 1.6-2.2\%.
Table 3 compares the proposed method with the other methods for the determination of ions.

\section{Multivariate calibration and Prediction set}

The first step in the simultaneous determination of $\mathrm{Co}^{2+}, \mathrm{Ni}^{2+}$ and $\mathrm{Cu}^{2+}$ in mixtures by multivariate methods involved constructing the calibration matrix. The multivariate calibration requires a careful experimental design of the standard composition of the calibration set for providing the best predictions. When working with three components (in this case cations), the experimental domain corresponds to a triangle. In our case, the range of variation of each cation was defined by a univariate calibration step $^{23}$. A training set of 21 samples was taken (Table 4).

In PLS model, the cross- validation (leave-one-out) method was used for selecting the number of factors and the predicted residual error sum of squares (PRESS) is calculated. One reasonable choice for the optimum number of factors would be that number which yielded the minimum PRESS.

In order to select the mixtures for prediction set, their compositions were randomly designed. For the evaluation of the predictive ability of a different model, the root mean square error of prediction (RMSEP) Equation (2) and relative standard error of prediction (RSEP) Equation (3) can be used:

$R M S E P=\sqrt{\frac{\sum_{i=1}^{n}\left(y_{i, p r e d}-y_{i, o b s}\right)^{2}}{n}}$

Table 3. Comparison of USAEME with other reported preconcentration techniques for $\mathrm{Co}^{2+}, \mathrm{Ni}^{2+}$ and $\mathrm{Cu}^{2+}$ determination

\begin{tabular}{|c|c|c|c|c|c|c|c|}
\hline Analytes & Method & $\begin{array}{c}\text { Detection } \\
\text { system }\end{array}$ & $\begin{array}{c}\text { Chelating } \\
\text { agent }\end{array}$ & $\mathrm{PF}^{\mathrm{a}}$ or $\mathrm{EF}^{\mathrm{b}}$ & 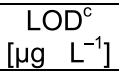 & $\operatorname{RSD}^{d}[\%]$ & Ref. \\
\hline $\mathrm{Co}^{2+}$ & \multirow{2}{*}{ DLLME } & \multirow{2}{*}{ FO-LADS } & \multirow{2}{*}{ PAN } & 165 & 0.2 & \multirow{2}{*}{$<4$} & \multirow{2}{*}{37} \\
\hline $\mathrm{Pd}^{2+}$ & & & & 162 & 0.25 & & \\
\hline $\mathrm{Ni}^{2+}$ & SPE & FAAS & PAN & 70 & 1.18 & $<1$ & 38 \\
\hline $\mathrm{Co}^{2+}$ & \multirow{2}{*}{ DLPME } & \multirow{2}{*}{ GFAAS } & \multirow{2}{*}{ PAN } & $101^{b}$ & 0.021 & 7.5 & \multirow{2}{*}{14} \\
\hline $\mathrm{Ni}^{2+}$ & & & & $200^{b}$ & 0.033 & 8.2 & \\
\hline $\mathrm{Co}^{2+}$ & DLLME & UV-Vis & PAN & $125^{b}$ & 0.5 & 2.5 & 39 \\
\hline $\mathrm{Co}^{2+}$ & \multirow{2}{*}{ CPE } & \multirow{2}{*}{ FO-LADS } & \multirow{2}{*}{ PAN } & 198 & 0.2 & \multirow{2}{*}{$<4$} & \multirow{2}{*}{40} \\
\hline $\mathrm{Ni}^{2+}$ & & & & 199 & 0.04 & & \\
\hline $\mathrm{Co}^{2+}$ & \multirow{3}{*}{ USAEME } & \multirow{3}{*}{ UV-Vis } & \multirow{3}{*}{ PAN } & \multirow{3}{*}{$200^{a}$} & 0.14 & 2.3 & \multirow{3}{*}{ This work } \\
\hline $\mathrm{Ni}^{2+}$ & & & & & 0.13 & 1.7 & \\
\hline $\mathrm{Cu}^{2+}$ & & & & & 0.14 & 1.2 & \\
\hline
\end{tabular}

${ }^{a}$ Preconcentration factor. ${ }^{b}$ Enrichment factor. ${ }^{c}$ Limit of detection. ${ }^{d}$ Relative standard deviation. GFAAS graphite furnace atomic absorption spectrometry. DLPME dispersive liquid phase microextraction. DLLME dispersive liquid-liquid microextraction. FO-LADS fiber optic-linear array detection spectrophotometry. SPE solid phase extraction. CPE cloud point extraction. USAEME ultrasound assistant emulsification microextraction.

Table 4. Concentration data of the different mixtures used in the calibration set for the determination of $\mathrm{Cu}^{2+}, \mathrm{Ni}^{2+}$ and $\mathrm{Co}^{2+}$ (ng $\mathrm{mL}^{-1}$ )

\begin{tabular}{|c|c|c|c|c|c|c|c|}
\hline Mixture & $\mathrm{Cu}^{2+}$ & $\mathrm{Ni}^{2+}$ & $\mathrm{Co}^{2+}$ & Mixture & $\mathrm{Cu}^{2+}$ & $\mathrm{Ni}^{2+}$ & $\mathrm{Co}^{2+}$ \\
\hline M1 & 2.0 & 2.0 & 150.0 & M12 & 2.0 & 96.0 & 30.0 \\
\hline M2 & 30.0 & 20.0 & 120.0 & M13 & 2.0 & 72.0 & 60.0 \\
\hline M3 & 60.0 & 2.0 & 90.0 & M14 & 2.0 & 48.0 & 90.0 \\
\hline M4 & 90.0 & 2.0 & 60.0 & M15 & 2.0 & 24.0 & 120.0 \\
\hline M5 & 120.0 & 2.0 & 30.0 & M16 & 30.0 & 24.0 & 90.0 \\
\hline M6 & 150.0 & 2.0 & 2.0 & M17 & 60.0 & 24.0 & 60.0 \\
\hline M7 & 120.0 & 24.0 & 2.0 & M18 & 90.0 & 24.0 & 36.0 \\
\hline M8 & 90.0 & 48.0 & 2.0 & M19 & 30.0 & 48.0 & 60.0 \\
\hline M9 & 60.0 & 72.0 & 2.0 & M20 & 60.0 & 48.0 & 30.0 \\
\hline M10 & 30.0 & 96.0 & 2.0 & M21 & 30.0 & 72.0 & 30.0 \\
\hline M11 & 2.0 & 120.0 & 2.0 & & & & \\
\hline
\end{tabular}


$\operatorname{RSEP}(\%)=100 \times \sqrt{\frac{\sum_{i=1}^{n}\left(y_{i, p r e d}-y_{i, o b s}\right)^{2}}{\sum\left(y_{i, o b s}\right)^{2}}}$

where $y_{i, \text { pred }}$ is the predicted concentration using different model, $y_{i, \text { obs }}$ is the actual concentration and $n$ is the number of compounds in the prediction set.

\section{Preprocessing by orthogonal signal correction}

Methods that find and extract variation with the property outlined above were originally called orthogonal signal correction (OSC) methods, or filters ${ }^{41}$. OSC is a preprocessing method for PLS regression to find variation in a descriptor matrix that is unrelated to that in a response matrix, and which therefore can be extracted and analyzed separately.

The results show that score plots have better results when OSC-PLS is used. Moreover, the OSC-filtered data give much simpler calibration models with fewer components than the ones based on the original data (Table 5).

\section{OSC-GA-PLS}

Variable selection is a critical step for increasing the predictive ability of multivariate analysis, and should ideally eliminate both uninformative and/or highly correlated data.

The OSC application to the calibration data implied that the OSC-PLS presents better results than PLS. In the other hand, GA can select suitable wavelengths. The results show that GA-PLS is a good method for the use of lower data, demonstrating more enhanced results in comparison with PLS. According to the above data, we decided to apply both OSC and GA in order to gain satisfactory results in the PLS application. Combining OSC and GA variable selection led to slightly better modeling and increased predictability. For calibration set, three OSC components were used for filtering. Evaluation of the prediction errors for the validation set reveals that the OSC-GA treated data give substantially lower the root mean square error of prediction (RMSEP) values prediction values than OSC-PLS data (Table 6).

\section{Real water sample analysis}

To validate the applicability of the method for simultaneous extraction and determination of $\mathrm{Co}^{2+}, \mathrm{Ni}^{2+}$ and $\mathrm{Cu}^{2+}$ in aqueous samples, waste water, well water and tap water were collected and analyzed with the proposed method. The results were shown in Table 7. The results indicated that there were no $\mathrm{Co}^{2+}, \mathrm{Ni}^{2+}$ and $\mathrm{Cu}^{2+}$ found in the samples. These samples were then spiked with $\mathrm{Co}^{2+}, \mathrm{Ni}^{2+}$ and $\mathrm{Cu}^{2+}$ at a different concentration to investigate the effect of sample matrices. As can be seen from Table 6, the spiked recoveries were satisfied in the range of $97.4-104.3 \%$ with the precisions of $0.9-1.7 \%$ (RSD), which indicated that USAEME combined with OSC-GA-PLS method was reliable and could be used for the trace analysis of $\mathrm{Co}^{2+}, \mathrm{Ni}^{2+}$ and $\mathrm{Cu}^{2+}$ in aqueous samples.

\section{CONCLUSIONS}

A novel and simple method based on ultrasoundassisted emulsification-microextraction (USAEME) combined with the spectrophotometric and OSC-GAPLS was evaluated for the preconcentration and the determination of trace $\mathrm{Cu}^{2+}, \mathrm{Ni}^{2+}$ and $\mathrm{Co}^{2+}$ from water samples. The USAEME method offered benefits such as low cost and no need for specialized instruments. In addition, it is important to point out that USAEME is

Table 5. Concentration data for prediction set mixtures of $\mathrm{Cu}^{2+}, \mathrm{Ni}^{2+}, \mathrm{Co}^{2+}$ and their predicted values $\left[\mathrm{ng} \mathrm{mL}^{-1}\right]$

\begin{tabular}{|c|c|c|c|c|c|c|c|c|c|c|c|c|c|c|c|}
\hline \multirow[t]{2}{*}{ Mixture } & \multicolumn{3}{|c|}{ True } & \multicolumn{3}{|c|}{$\begin{array}{l}\text { Predicted } \\
\text { [PLS] }\end{array}$} & \multicolumn{3}{|c|}{$\begin{array}{l}\text { Predicted } \\
\text { [OSC-PLS] }\end{array}$} & \multicolumn{3}{|c|}{$\begin{array}{c}\text { Predicted } \\
\text { [OSC-GA-PLS] }\end{array}$} & \multicolumn{3}{|c|}{ Recovery [\%] } \\
\hline & $\mathrm{Cu}^{2+}$ & $\mathrm{Ni}^{2+}$ & $\mathrm{Co}^{2+}$ & $\mathrm{Cu}^{2+}$ & $\mathrm{Ni}^{2+}$ & $\mathrm{Co}^{2+}$ & $\mathrm{Cu}^{2+}$ & $\mathrm{Ni}^{2+}$ & $\mathrm{Co}^{2+}$ & $\mathrm{Cu}^{2+}$ & $\mathrm{Ni}^{2+}$ & $\mathrm{Co}^{2+}$ & $\mathrm{Cu}^{2+}$ & $\mathrm{Ni}^{2+}$ & $\mathrm{Co}^{2+}$ \\
\hline \begin{tabular}{|l|} 
M22 \\
\end{tabular} & 40.0 & 60.0 & 100.0 & 47.8 & 76.2 & 82.4 & 45.2 & 71.2 & 88.4 & 39.6 & 61.2 & 96.5 & 99.0 & 102.0 & 96.5 \\
\hline M23 & 100.0 & 20.0 & 40.0 & 106.0 & 16.8 & 43.3 & 102.1 & 17.2 & 42.3 & 102.3 & 20.3 & 39.9 & 102.3 & 101.5 & 99.7 \\
\hline M24 & 140.0 & 60.0 & 80.0 & 126.1 & 68.2 & 89.3 & 132.2 & 64.5 & 85.2 & 138.6 & 59.2 & 81.2 & 99.0 & 98.6 & 101.5 \\
\hline M25 & 20.0 & 40.0 & 60.0 & 26.1 & 43.7 & 69.3 & 24.1 & 42.6 & 65.2 & 21.0 & 39.1 & 61.2 & 105.0 & 97.7 & 102.0 \\
\hline \begin{tabular}{|l|} 
M26 \\
\end{tabular} & 80.0 & 120.0 & 20.0 & 75.1 & 145.2 & 18.5 & 76.2 & 129.8 & 18.9 & 81.2 & 122.6 & 19.8 & 101.5 & 102.2 & 99.0 \\
\hline \begin{tabular}{|l|} 
M27 \\
\end{tabular} & 120.0 & 40.0 & 10.0 & 123.3 & 44.1 & 12.5 & 115.2 & 35.8 & 12.0 & 120.8 & 38.9 & 10.2 & 100.6 & 97.2 & 102.0 \\
\hline \begin{tabular}{|l|} 
M28 \\
\end{tabular} & 60.0 & 60.0 & 40.0 & 66.5 & 41.3 & 36.9 & 65.2 & 53.2 & 38.1 & 60.2 & 58.6 & 39.1 & 100.3 & 97.7 & 97.8 \\
\hline
\end{tabular}

Table 6. Statistical parameters obtained by applying the three methods

\begin{tabular}{|l|c|c|c|c|c|c|c|c|c|}
\hline \multirow{2}{*}{ Methods } & \multicolumn{3}{|c|}{$\mathrm{PLS}$} & \multicolumn{3}{c|}{$\mathrm{OSC}-\mathrm{PLS}$} & \multicolumn{3}{c|}{ OSC-GA-PLS } \\
\cline { 2 - 11 } & $\mathrm{Cu}^{2+}$ & $\mathrm{Ni}^{2+}$ & $\mathrm{Co}^{2+}$ & $\mathrm{Cu}^{2+}$ & $\mathrm{Ni}^{2+}$ & $\mathrm{Co}^{2+}$ & $\mathrm{Cu}^{2+}$ & $\mathrm{Ni}^{2+}$ & $\mathrm{Co}^{2+}$ \\
\hline $\mathrm{NF}^{\mathrm{a}}$ & 5 & 5 & 5 & 4 & 4 & 4 & 3 & 3 & 3 \\
\hline PRESS & 5.14 & 9.67 & 9.94 & 4.38 & 2.73 & 3.06 & 2.39 & 1.08 & 1.79 \\
\hline RMSEP & 7.61 & 14.07 & 8.55 & 4.9 & 6.79 & 5.37 & 1.24 & 1.45 & 1.51 \\
\hline RSEP\% & 8.54 & 21.93 & 14.69 & 5.56 & 10.58 & 9.23 & 1.37 & 2.25 & 2.62 \\
\hline
\end{tabular}

${ }^{a}$ Number of factor.

Table 7. Determination of $\mathrm{Cu}^{2+}, \mathrm{Ni}^{2+}$ and $\mathrm{Co}^{2+}$ in real water samples

\begin{tabular}{|c|c|c|c|c|c|c|c|c|c|c|c|c|}
\hline & \multicolumn{3}{|c|}{ Added [ng $\left.\mathrm{mL}^{-1}\right]$} & \multicolumn{3}{|c|}{ Found [ng $\mathrm{mL}^{-1}$ ] } & \multicolumn{3}{|c|}{ Recovery [\%] } & \multicolumn{3}{|c|}{ RSD [\%] } \\
\hline & $\mathrm{Cu}^{2+}$ & $\mathrm{Ni}^{2+}$ & $\mathrm{Co}^{2+}$ & $\mathrm{Cu}^{2+}$ & $\mathrm{Ni}^{2+}$ & $\mathrm{Co}^{2+}$ & $\mathrm{Cu}^{2+}$ & $\mathrm{Ni}^{2+}$ & $\mathrm{Co}^{2+}$ & $\mathrm{Cu}^{2+}$ & $\mathrm{Ni}^{2+}$ & $\mathrm{Co}^{2+}$ \\
\hline \multirow{2}{*}{ Waste water } & 0.0 & 0.0 & 0.0 & $N D^{a}$ & ND & ND & - & - & - & - & - & - \\
\hline & 80.0 & 80.0 & 80.0 & 82.2 & 83.4 & 81.1 & 102.8 & 104.3 & 101.4 & 0.9 & 1.5 & 1.4 \\
\hline \multirow{2}{*}{ Well water } & 0.0 & 0.0 & 0.0 & ND & ND & ND & - & - & - & - & - & - \\
\hline & 60.0 & 40.0 & 60.0 & 61.1 & 41.6 & 59.8 & 101.8 & 104.1 & 99.7 & 1.1 & 1.6 & 1.3 \\
\hline \multirow{2}{*}{ Tap water } & 0.0 & 0.0 & 0.0 & ND & ND & ND & - & - & - & - & - & - \\
\hline & 60.0 & 100.0 & 40.0 & 58.9 & 102.3 & 38.9 & 98.2 & 102.3 & 97.4 & 1.6 & 1.3 & 1.5 \\
\hline
\end{tabular}

\footnotetext{
${ }^{\mathrm{a}}$ Not detection.
} 
a low organic solvent consuming extraction technique, which turns it into an environmentally friendly technique. In this method, the consumption of the toxic organic solvent (at $\mu \mathrm{L}$ level) was minimized without affecting the method sensitivity. The application of a Box-Behnken matrix became the possible, rapid, economical and efficient way of an optimization strategy of the proposed procedure. The $\mathrm{Cu}^{2+}, \mathrm{Ni}^{2+}$ and $\mathrm{Co}^{2+}$ mixture based on their complexation with the common reagent PAN, due to the high spectral overlapping observed between the absorption spectra, is a complex system. For overcoming the drawback of spectral interferences, PLS multivariate calibration method is applied. Also, the present study shows that the GAs can be a good method for feature selection in spectral data sets. Analysis of the results for mixtures showed that the use of GA-PLS leads to the better prediction compared to the PLS method. The predicted values are obtained by the application of OSC-GA-PLS model for absorbance data showed the prediction ability of the OSC-GA-PLS method much improvement compared to the GA-PLS method. The method can be successful offers a good selectivity for the simultaneous determination of $\mathrm{Co}^{2+}, \mathrm{Ni}^{2+}$ and $\mathrm{Cu}^{2+}$ in the presence of a variety of metal ions in real water samples.

\section{ACKNOWLEDGEMENT}

The author is gratefully acknowledging the support of this work by the Islamic Azad University, Arak Branch.

\section{LITERATURE CITED}

1. Hedberg, Y., Herting, G. \& Wallinder, I.O. (2011). Risks of using membrane filtration for trace metal analysis and assessing the dissolved metal fraction of aqueous media - A study on zinc, copper and nickel. Environ. Pollut. 159(5), 1144-1150. DOI: 10.1016/j.envpol.2011.02.014.

2. Şengil, I.A. \& Özacar, M. (2008). Biosorption of $\mathrm{Cu}(\mathrm{II})$ from aqueous solutions by mimosa tannin gel. J. Hazard. Mater. 157(2-3), 277-285. DOI: 10.1016/j.jhazmat.2007.12.115.

3. Regueiroa, J., Lomparta, M., Garcia-Jaresa, C., GarciaMonteagudob, J.C. \& Celaa, R. (2008). Ultrasound-assisted emulsification-microextraction of emergent contaminants and pesticides in environmental waters. J. Chromatogr. A 1190(1-2), 27-38. DOI: 10.1016/j.chroma.2008.02.091.

4. Feng, J., Qiu, H., Liu, X. \& Jiang, Sh. (2013). The development of solid-phase microextraction fibers with metal wires as supporting substrates. TrAC, Trends Anal. Chem. 46, 44-58. DOI: 10.1016/j.trac.2013.01.015.

5. Su, Sh., Chen, B., He, M. \& Hu, B. (2014). Graphene oxide-silica composite coating hollow fiber solid phase microextraction online coupled with inductively coupled plasma mass spectrometry for the determination of trace heavy metals in environmental water samples. Talanta 123, 1-9. DOI: 10.1016/j. talanta.2014.01.061.

6. Miró, M. \& Hansen, E.H. (2013). On-line sample processing involving microextraction techniques as a front-end to atomic spectrometric detection for trace metal assays: A review. Anal. Chim. Acta 782, 1-11. DOI: 10.1016/j.aca.2013.03.019.

7. Sereshti, H., Khojeh, V. \& Samadi, S. (2011). Optimization of dispersive liquid-liquid microextraction coupled with inductively coupled plasma-optical emission spectrometry with the aid of experimental design for simultaneous determination of heavy metals in natural waters. Talanta 83(3), 885-890. DOI: 10.1016/j.talanta.2010.10.052.
8. Mirzaei, M., Behzadi, M., Mahmoud Abadi, N. \& Beizaei, A. (2011). Simultaneous separation/preconcentration of ultra-trace heavy metals in industrial wastewaters by dispersive liquid-liquid microextraction based on solidification of floating organic drop prior to determination by graphite furnace atomic absorption spectrometry. J. Hazard. Mater. 186(2-3), 1739-1743. DOI: 10.1016/j.jhazmat.2010.12.080,

9. Stanisz, E., Werner, J. \& Zgoła-Grześkowia, A. (2014). Liquid-phase microextraction techniques based on ionic liquids for preconcentration and determination of metals. TrAC, Trends Anal. Chem. 61, 54-66. DOI: 10.1016/j.trac.2014.06.008.

10. Deng, Q., Chen, M., Kong, L., Zhao, X., Guo, J. \& Wen, X. (2013). Novel coupling of surfactant assisted emulsification dispersive liquid-liquid microextraction with spectrophotometric determination for ultra-trace nickel. Spectrochim. Acta, Part A 104, 64-69. DOI: 10.1016/j.saa.2012.10.080.

11. Rezaee, M., Assadi, Y., Milani Hosseini, M.R., Aghaee, E., Ahmadi, F. \& Berijani, S., (2006). Determination of organic compounds in water using dispersive liquid-liquid microextraction. J. Chromatogr. A 1116(1-2), 1-9. DOI: 10.1016/j. chroma.2006.03.007.

12. Takagai, Y., Akiyama R. \& Igarashi, S. (2006). Powerful preconcentration method for capillary electrophoresis and its application to ultra-trace amounts of polycyclic aromatic hydrocarbons analyses. Anal. Bioanal. Chem. 385(5), 888-894. DOI: 10.1007/s00216-006-0447-9.

13. Andruch, V., Balogh, I.S., Burdel, M., Kocúrová, L. \& Šandrejová, J. (2013). Application of ultrasonic irradiation and vortex agitation in solvent microextraction. TrAC, Trends Anal. Chem. 49, 1-19. DOI: org/10.1016/j.trac.2013.02.006.

14. Jiang, H., Qin, Y. \& Hu, B. (2008). Dispersive liquid phase microextraction (DLPME) combined with graphite furnace atomic absorption spectrometry (GFAAS) for determination of trace $\mathrm{Co}$ and $\mathrm{Ni}$ in environmental water and rice samples. Talanta 74(5), 1160-1165. DOI: 10.1016/j.talanta.2007.08.022.

15. Anthemidis, A.N. \& Ioannou, K.I.G. (2011). Sequential injection dispersive liquid-liquid microextraction based on fatty alcohols and poly(etheretherketone)-turnings for metal determination by flame atomic absorption spectrometry. Talanta 84, 1215-1220. DOI: 10.1016/j.talanta.2010.12.017.

16. Sereshti, H., Entezari Heravi, Y. \& Samadi, S. (2012). Optimized Ultrasound-Assisted Emulsification Microextraction for Simultaneous Trace Multielement Determination of Heavy Metals in Real Water Samples by ICP-OES. Talanta 97, 235-241. DOI: org/10.1016/j.talanta.2012.04.024.

17. Oliveira, E.P., Yang, L., Sturgeon, R.E., Santelli, R.E., Bezerra, M.A., Willie, S.N. \& Capilla, R. (2011). Determination of trace metals in high-salinity petroleum produced formation water by inductively coupled plasma mass spectrometry following on-line analyte separation/preconcentration. J. Anal. At. Spectrom. 26(3), 578-585. DOI: 10.1039/c0ja00108b.

18. Karim-Nezhad, G., Saghatforoush L. \& Ershad, S. (2009). Simultaneous Determination of Copper and Iron in Biological Samples with 1-(2-Pyridylazo)-2-naphthol in Anionic AOT Micellar Solution Using Derivative Spectrophotometry. Asian J. Chem. 21(2), 2565-2572.

19. Niazi, A. \& Yazdanipour, A. (2008). Simultaneous spectrophotometric determination of cobalt, copper and nickel using 1-(2-thiazolylazo)-2-naphthol by chemometrics methods. Chin. Chem. Lett. 19(7), 860-864. DOI: 10.1016/j.cclet.2008.04.047.

20. Saavedra, R., Soto, C., Gómez, R. \& Muñoz, A. (2013). Determination of lead(II) by thermal lens spectroscopy (TLS) using 2-(2'-thiazolylazo)-p-cresol (TAC) as chromophore reagent. Microchem. J. 110, 308-313. DOI: 10.1016/j. microc.2013.04.019.

21. Niazi, A. \& Azizi, A. (2008). Orthogonal Signal Correction - Partial Least Squares Method for Simultaneous Spectrophotometric Determination of Nickel, Cobalt, and Zinc. Turk. J. Chem. 32, 217-228. 
22. Hejazi, L., Mohammadi, D.E., Yamini, Y. \& Brereton, R.G. (2004). Solid-phase extraction and simultaneous spectrophotometric determination of trace amounts of $\mathrm{Co}, \mathrm{Ni}$ and $\mathrm{Cu}$ using partial least squares regression. Talanta 62(1), 185-191 DOI: 10.1016/S0039-9140(03)00412-0.

23. Niazi, A., Azizi A. \& Ramezani, M. (2008). Simultaneous spectrophotometric determination of mercury and palladium with Thio-Michler's Ketone using partial least squares regression and orthogonal signal correction. Spectrochim. Acta, Part A 71 (3), 1172-1177. DOI: 10.1016/j.saa.2008.03.017.

24. Niazi, A. (2006). Simultaneous Determination of Uranium and Thorium Using Partial Least Squares Regression and Orthogonal Signal Correction. J. Braz. Chem. Soc. 17, 1020-1026. DOI: org/10.1590/S0103-50532006000500029.

25. Tarighat, M.A. \& Afkhami, A. (2012). Spectrophotometric Determination of $\mathrm{Cu}(\mathrm{II}), \mathrm{Co}(\mathrm{II})$ and $\mathrm{Ni}(\mathrm{II})$ using Ratio Spectra Continuous Wavelet Transformation in some Food and Environmental Samples. J. Braz. Chem. Soc. 23, 1312-1319. DOI: org/10.1590/S0103-50532012000700016.

26. Leardi, R. (2001). Genetic algorithms in chemometrics and chemistry: a review. J. Chemom. 15, 559-569. DOI: 10.1002/cem.651.

27. Ghasemi, J., Niazi A. \& Leardi, R. (2003). Genetic-algorithm-based wavelength selection in multicomponent spectrophotometric determination by PLS: application on copper and zinc mixture. Talanta 59(2), 311-317. DOI:10.1016/ S0039-9140(02)00505-2.

28. Niazi, A., Soufi, A. \& Mobarakabadi, M. (2006). Genetic Algorithm Applied to Selection of Wavelength in Partial Least Squares for Simultaneous Spectrophotometric Determination of Nitrophenol Isomers. Anal. Lett. 39(11), 2359-2372. DOI: $10.1080 / 00032710600751016$.

29. Ghasemi, J., Ebrahimi, D.M., Hejazi, L., Leardi R. \& Niazi, A. (2007). Simultaneous kinetic-spectrophotometric determination of sulfide and sulfite by partial least squares and genetic algorithm variable selection. J. Anal. Chem. 62 (4), 348-354. DOI: 10.1134/S1061934807040090.

30. Niazi, A. \& Leardi, R. (2012). Genetic algorithms in chemometrics. J. Chemom. 26(6), 345-351. DOI: 10.1002/cem.2426.

31. Karbakhsh, R. \& Sabet, R. (2011). Application of different chemometric tools in QSAR study of azoloadamantanes against influenza A virus. Res. Pharm. Sci. 6(1), 23-33.

32. Lurie, J.J. (1978). Handbook of Analytical Chemistry. Moscow: Mir Publishers.

33. Niazi, A., Khorshidi N. \& Ghaemmaghami, P. (2015). Microwave-assisted of dispersive liquid-liquid microextraction and spectrophotometric determination of uranium after optimization based on Box-Behnken design and chemometrics methods. Spectrochim. Acta, Part A 135, 69-75. DOI: 0.1016/j. saa.2014.06.148.

34. Box, E.P. \& Behnken, D. W. (1960). Some new three-level designs for the study of quantitative variables. Technometrics $2,455-475$.

35. Chopra, S., Patil, G.V. \& Motwani, S.K. (2007). Release modulating hydrophilic matrix systems of losartan potassium: optimization of formulation using statistical experimental design. Eur. J. Pharm. Biopharm. 66(1), 73-82. DOI: 10.1016/j. ejpb.2006.09.001.

36. Yetilmezsoy, K., Demirel, S. \& Vanderbei, R.J. (2009). Response surface modeling of $\mathrm{Pb}$ (II) removal from aqueous solution by Pistacia vera L.: Box-Behnken experimental design. J. Hazard. Mater. 171(1-3), 551-562. DOI: 10.1016/j. jhazmat.2009.06.035.

37. Shokoufi, N., Shemirani, F. \& Assadi, Y. (2007). Fiber optic-linear array detection spectrophotometry in combination with dispersive liquid-liquid microextraction for simultaneous preconcentration and determination of palladium and cobalt. Anal. Chim. Acta 597(2), 349-356. DOI: 10.1016/j. aca.2007.07.009.
38. Jaggi, S. \& Gupta, U. (2013). Solid phase extraction and preconcentration of $\mathrm{Ni}(\mathrm{II})$ using 1-(2-pyridylazo)-2-naphthol) (PAN) modified $\beta$-cyclodextrin butanediol diglycidyl ether polymer as a solid phase extractant. Maced. J. Chem. Chem. En. 32(1), 57-67.

39. Gharehbaghi, M., Shemirani, F. \& Baghdadi, M. (2008). Dispersive liquid-liquid microextraction and spectrophotometric determination of cobalt in water samples. Int. J. Environ. Anal. Chem. 88, 513-523. DOI: 10.1080/03067310701809128.

40. Shokoufi, N., Shemirani, F. \& Memarzadeh, F. (2007). Fiber optic-linear array detection spectrophotometry in combination with cloud point extraction for simultaneous preconcentration and determination of cobalt and nickel. Anal. Chim. Acta 601(2), 204-211. DOI: 10.1016/j.aca.2007.08.042.

41. Wold, S., Antii, H., Lindgren, F. \& Ohman, J. (1998). Orthogonal signal correction of near-infrared spectra. Chemom. Intell. Lab. Syst. 44, 175-185. 